\title{
O CUIDADO DE CRIANÇAS HOSPITALIZADAS COM CONDIÇÕES CRÔNICAS COMPLEXAS: VIVÊNCIAS E APRENDIZAGEM
}

\section{THE CARE FOR HOSPITALIZADED CHILDREN WIHT COMPLEX CHRONIC DISEASE: EXPERIENCES AND LEARNING}

\author{
Rosilene Aparecida dos Santos ${ }^{1}$ \\ Maria Cecília de Souza Minayo ${ }^{2}$
}

\begin{abstract}
Resumo: Esse artigo apresenta e discute a relação subjetiva e intersubjetiva dos profissionais de saúde com crianças com condições crônicas complexas de saúde e suas famílias. É parte de uma pesquisa qualitativa, construída a partir do método etnográfico, numa enfermaria de pediatria de um hospital federal do Rio de Janeiro. Buscou-se entender a lógica e lacunas do cuidado hospitalar, principalmente voltada para as questões subjetivas das crianças. O estudo permitiu vários tipos de observação, que estão organizados em três tópicos: 1) Movimentos, atores e intervenções: observando o cenário, fruto de observação participante; 2) Olhar, compreender, interagir e respeitar: ouvindo quem cuida; 3) Aprender, compreender, interpretar e agir. As habilidades profissionais para o cuidado integral dessas crianças são construídas cotidianamente, baseadas nas necessidades de cada uma, englobando os aspectos físicos, subjetivos, coletivos e história de vida. A subjetividade e intersubjetividade são a alma propulsora da dinâmica da vida na enfermaria.
\end{abstract}

Palavras-chave: Hospitalização; Pediatria; Doença crônica; Assistência hospitalar; Sistema de aprendizagem em saúde.

\begin{abstract}
This article presents and discusses the subjective and intersubjective relationship between health professionals and hospitalized children with complex chronic health conditions and their families. This is part of a qualitative research, built from ethnografic method, in a pediatric ward of a federal hospital in Rio de Janeiro. Was sought the understanding of logic and deficiencies of hospital care, focusing mainly on subjective issues of children. This research allowed types of observations, that are organized in three topics: Movements, actors and interventions: Observing the setting, result of participant observation; Looking, understanding, interpreting and acting: listening to the ones who provide the care; Learning, understanding, interpreting, acting. The professional skills for comprehensive care of these children are built daily, based on the needs of each one them, encompassing their physical, subjective, collective aspects and their life history. The subjectivity and intersubjectivity are the propelling soul of dynamics of life in the ward.
\end{abstract}

Keywords: Hospitalization; Pediatrics; Chronic Disease; Hospital Care; Learning Health Systen.

\footnotetext{
${ }^{1}$ Doutoranda em Saúde Coletiva pelo Instituto Nacional de Saúde da Criança, da Mulher e do Adolescente Fernandes Figueira (IFF/FIOCRUZ). Técnica em Saúde Pública do IFF/FIOCRUZ. Rio de Janeiro, RJ, Brasil. E-mail: rosi.aps30@gmail.com

${ }^{2}$ Doutora em Saúde Pública pela Fundação Oswaldo Cruz (FIOCRUZ). Pesquisadora titular do Centro Latino-Americano de Estudos de Violência e Saúde (CLAVES/FIOCRUZ). Rio de Janeiro, RJ, Brasil. Email: maminayo@terra.com.br
} 


\section{Introdução}

Esse artigo apresenta e discute a relação subjetiva e intersubjetiva dos profissionais de saúde com crianças com condições crônicas complexas de saúde e suas famílias. Os dados foram gerados a partir de um estudo etnográfico, numa enfermaria pediátrica, ambiente em que profissionais, técnicos e familiares transitam, e existe forte interação com tecnologias médicas e relacionais.

A subjetividade é o espaço íntimo do sujeito, constituído por aspectos individuais e coletivos, que influenciam nos modos de ver, sentir e ser. A intersubjetividade, configura uma condição da vida social que permite o compartilhamento de sentidos, experiências e conhecimentos entre os sujeitos (SANTOS; KOEPPE; CARVALHO, 2020; MELLO et al., 2017).

O hospital é uma organização complexa de saúde, composta por profissionais formados para a atenção e gestão e para uso de diversas tecnologias. Ele funciona também como um espaço de aprendizagem para formação técnica, de graduação e de pósgraduação (FEUERWERKER; CECÍLIO, 2007). Uma das características desse espaço de formação é o fato de o conhecimento técnico e científico, frequentemente ser construído ao mesmo tempo em que a assistência aos usuários é prestada. Desta forma, o hospital pode ser considerado um "laboratório vivo", potente e desafiante. Como ressalta Merhy (2014, p. 48) "O trabalho em saúde é centrado no trabalho vivo em ato permanentemente, um pouco à semelhança do trabalho em educação". Nesse espaço organizacional, a concepção da integralidade (CECÍLIO; MERHY, 2003) e da humanização (DESLANDES, 2008) dos cuidados deve ser trabalhada permanentemente para que estudantes e profissionais estejam aptos a atender às demandas da clínica física e subjetiva dos usuários.

Compreender a subjetividade do outro, naturalmente, é difícil. Como lembra Gadamer (1999), exige um esforço de colocar-se no lugar daquela pessoa, o que demanda um olhar sensível. Nas unidades de internação pediátrica o desafio parece ser maior, em especial quando a maioria das meninas e meninos possui condições crônicas complexas de saúde, apresentando limitações ou impossibilidades de comunicação verbal e não verbal. Menezes et al., (2019) contextualizam a condição complexa de saúde como uma situação de adoecimento crônico caracterizada por períodos longos (duração mínima de 12 meses), comprometimento orgânico de um ou mais órgãos ou sistemas, necessidade de acompanhamento especializado e cuidados permanentes, dependência tecnológica e 
possível necessidade de suporte de média e alta complexidade. O quadro é mais delicado do que o dos adultos, porque o adoecimento e as necessidades de tratamento incidem sobre o crescimento e o desenvolvimento físico, mental e emocional na infância.

Refletir sobre as posições da criança hospitalizada, como "objeto de aprendizado e de trabalho" é uma oportunidade de rever comportamentos, práticas e interações, a favor de um cuidado adequado e empático. A produção da subjetividade e a constituição dos sujeitos são constantes, irregulares, inacabadas, dependentes dos discursos, posições, relações e meio em que eles estão inseridos (FERNANDES, 2012). O entendimento sobre a construção do sujeito no hospital e os impactos da hospitalização no seu desenvolvimento merecem destaque.

De forma geral, o corpo está imerso num campo político, marcado por produções sociais, linguagens, enunciados e hábitos (FOUCAUL, 1999). No caso de um hospital, ele é um lócus em que os discursos e saberes especializados, se estiverem apenas dentro da lógica biomédica, atenderão as pessoas como órgãos ou funções com algum tipo de falha que precisa ser corrigida ou remediada.

O estudo permitiu vários tipos de observação que aqui estão organizados em três tópicos: (1) Movimentos, atores e intervenções: observando o cenário, fruto de observação participante; (2) Olhar, compreender, interagir e respeitar: ouvindo quem cuida, resultado de entrevistas; (3) Aprender, compreender, interpretar e agir: a práxis do profissional de saúde, momento em que se analisa como o cotidiano de um trabalho tão difícil e complexo como o de uma enfermaria infantil contribui para o enriquecimento humano e relacional dos profissionais.

\section{Método e processo de produção dos dados}

Este artigo é parte de uma pesquisa de cunho qualitativo, construída a partir do método etnográfico, numa enfermaria de pediatria de um hospital federal do Rio de Janeiro que atua em assistência, ensino e pesquisa.

O método foi escolhido por possibilitar a observação em tempo real da realidade, por meio da imersão da pesquisadora na observação participante e união do pilar teórico com as observações relatadas em diário de campo e entrevistas semiestruturadas (ANDRADE; MALUF, 2014; GEERTZ, 1978).

É importante sublinhar que a observação participante é uma técnica muito produtiva no ambiente hospitalar (MINAYO, 2019). O ver, o sentir e o conviver no local 
onde um estudo qualitativo se realiza são ações e atitudes fundamentais da pesquisa social compreensiva e empírica. E a melhor forma de definir esse termo é apresentada no clássico pensamento de Malinowski, o antropólogo mais famoso na definição de métodos e técnicas que contemplam o olhar e a convivência em campo:

\begin{abstract}
Há una série de fenômenos de grande importância que não podem ser registrados por meio de perguntas ou de documentos quantitativos, mas devem ser observados em sua realidade. Denominemo-los "imponderáveis da vida real". Entre eles se incluem coisas como a rotina de um dia de trabalho, detalhes do cuidado com o corpo, forma de comer e de preparar a comida; tom das conversas e da vida social ao redor das casas, a existência de grandes hostilidades, simpatias e antipatias entre as pessoas; a forma sutil mais inquestionável em que as vaidades e ambições pessoais se refletem no comportamento dos indivíduos e as reações emocionais dos que os rodeiam (MALINOWSKI, 2005, p. 55).
\end{abstract}

Malinowski faz uma crítica radical aos tipos de investigação social que apreendem somente o nível mais aparente da realidade. Considera que esse tipo de fazer ciência percebe só o esqueleto da sociedade e não atinge a vida que nela palpita, porque fica longe do lugar onde o poder, as trocas, as relações e os sentimentos acontecem. Valorizando a importância de ouvir as pessoas, da observação direta e, ao mesmo tempo, do papel do pesquisador em campo, Malinowski (2005) ressalta: "toda a estrutura de uma sociedade se encontra incorporada no mais evasivo de todos os materiais: o ser humano".

Esse autor ensina o que observar numa realidade empírica determinada: (a) o conjunto de regras formuladas ou implícitas com as quais se guiam os componentes do grupo social; (b) a forma como essas regras são obedecidas ou transgredidas; (c) os sentimentos de amizade, de antipatia ou simpatia que permeiam os membros da coletividade; (d) os aspectos legais e os aspectos íntimos das relações sociais; (e) as tradições e os costumes e a importância que lhes são atribuídos; (f) as ideias, os motivos e os sentimentos do grupo na compreensão da vida, verbalizados ou evidenciados em gestos, atitudes e categorias de pensamento. Apesar de propor um roteiro de observação, esse autor ensina que o pesquisador deve experimentar a tensão entre uma rigorosa preparação teórica e uma total abertura para o que a livre vivência no campo lhe oferecer. E se for preciso, deve abrir mão de alguma coisa, que seja de suas teorias. Mas, nunca, da compreensão da realidade (MINAYO, 2019). Esse foi o caminho seguido neste trabalho.

Os dados foram coletados e construídos entre março e julho de 2020. As entrevistas que acompanharam a observação foram feitas com: uma enfermeira plantonista, uma enfermeira que está no $2^{\circ}$ ano de residência, uma fisioterapeuta, uma nutricionista, uma médica e dois técnicos de enfermagem. Os nomes que referenciam os 
participantes são fictícios. As observações e entrevistas foram feitas pela doutoranda Rosilene Aparecida dos Santos. A pesquisa foi orientada pela Dra. Maria Cecília de Souza Minayo.

O critério de inclusão para as entrevistas foi: ser profissional de saúde atuante na assistência à clientela pediátrica da unidade estudada. Por se tratar de um estudo etnográfico, houve observação e conversas informais com a maioria dos atores desse cenário. Em todas as oportunidades foi comunicado o porque da presença e das intenções da pesquisadora. Não houve nenhuma rejeição em participar da pesquisa.

Buscou-se entender a lógica e lacunas do cuidado hospitalar, principalmente voltada para as questões subjetivas das crianças. Para Minayo:

\begin{abstract}
A atitude de observador científico consiste em colocar-se do ponto de vista do grupo pesquisado, com respeito, empatia e inserção, o mais intima e mais intensamente possível. Significa, por parte do pesquisador, ter abertura para o grupo, sensibilidade para sua lógica e para sua cultura, lembrando-se de que a interação social faz parte da condição e da situação da pesquisa (MINAYO, 2008, p. 277).
\end{abstract}

Foram cumpridas todas as exigências da Resolução N.466 de 12 de dezembro de 2012 (BRASIL, 2012), que regulamenta a Pesquisa com Seres Humanos e da Resolução N.510 de 07 de abril de 2016 (BRASIL, 2016), que regulamenta a Pesquisa em Ciências Humanas e Sociais. Foram respeitados os princípios da: autonomia, não maleficência, beneficência, justiça e equidade. Foram assegurados os direitos e deveres que dizem respeito aos participantes da pesquisa, à comunidade científica e ao Estado (BRASIL, 2012). A pesquisa foi avaliada pelo Comitê de Ética em Pesquisa Institucional e aprovada sob o Parecer: 3.851 .868$.

\title{
3 Resultados
}

O estudo permitiu vários tipos de observação, que estão organizados e discutidos em três tópicos: (4.1) Movimentos, atores e intervenções: observando o cenário, fruto de observação participante; (4.2) Olhar, compreender, interagir e respeitar: ouvindo quem cuida, resultado de entrevistas; (4.3) Aprender, compreender, interpretar e agir: a práxis do profissional de saúde, momento em que se analisa como o cotidiano de um trabalho tão difícil e complexo como o de uma enfermaria infantil contribui para o enriquecimento humano e relacional dos profissionais. 


\section{Discussão}

\subsection{Movimentos, atores e intervenções: observando o cenário}

A imersão na unidade de internação pediátrica (enfermaria) possibilitou a observação em tempo real dos fenômenos e conversas com usuários, familiares e profissionais (de saúde e dos serviços gerais) que ali trabalham.

O cenário é composto por 18 leitos, divididos em: 7 boxes separados por vidro (dois leitos em cada) e um espaço subdividido no final da enfermaria (com 4 leitos, separados por cortinas). Devido a essa estrutura física, a assistência e o fluir da vida nesse espaço são "públicos", não havendo privacidade para as crianças e acompanhantes. Há disponibilidade de uma cadeira acolchoada, ao lado de cada leito, para os acompanhantes. Nem todas as crianças permanecem acompanhadas diariamente.

O fluxo de pessoas é intenso, principalmente na parte da manhã, momento em que os médicos examinam as crianças, há maior atuação multiprofissional (enfermagem, fisioterapia respiratória e motora, terapia ocupacional, nutrição, assistência social), rotina de cuidados, reposição de material de consumo, e outros. Os turnos da tarde e noite são mais tranquilos, permanecendo na unidade apenas os profissionais considerados "essenciais" para a assistência: profissionais de enfermagem (enfermeiro e técnicos de enfermagem), equipe médica (um médico da instituição e residentes) e profissionais dos serviços gerais (geralmente duas mulheres). Essas equipes trabalham em regime de plantão de 12 ou de 24 horas. Esse espaço, por se caracterizar como também de ensino, é campo para atuação para residentes das diversas áreas da saúde, sendo a maioria de medicina e de enfermagem.

Sobre o trabalho assistencial com essas crianças observa-se a intensidade do contato direto, físico e relacional. A prática cotidiana engloba rotinas e imprevisibilidades comuns à fluidez da clínica e da intersubjetividade. Como rotina, tem-se a organização do cuidado (medicamentos, verificação dos sinais vitais, banho, higiene corporal, curativos, punções venosas, inserção de sonda nasoenteral, cateterismo vesical de alívio, coleta de sangue, e outros). E como imprevisibilidades, acontecem abruptas e graves alterações de quadro clínico; expressões emocionais "mais exacerbadas" dos usuários ou acompanhantes; divergências na escolha de condutas clínicas por parte dos profissionais; questionamentos, resistências e negações por parte de usuários ou familiares quanto à terapêutica. 
A compreensão, empatia e compaixão são habilidades básicas para o cuidar, que mesmo quando subsidiado por procedimentos ou tecnologias duras, é precedido por relações humanas. Arantes (2019, p. 54) explica que, "na empatia a pessoa se coloca no lugar do outro e na compaixão, primeiro se sabe quem é e do que se é capaz para depois ir ao encontro do outro". Os pilares da intersubjetividade, representados pelas dimensões do afeto, da defesa dos direitos e da estima social (MELLO et al., 2017) são um norte para que nesse campo de cuidado as necessidades dos usuários sejam contempladas.

A hospitalização na infância é desafiadora e está relacionada com modificação de hábitos e rotinas, separação de pessoas e contextos, perda de autonomia e submissão a procedimentos estressantes e dolorosos. As formas de enfrentamento e adaptação estão associadas à idade, experiências, maturidade, situação clínica e, principalmente, ao suporte físico e emocional a que a criança tem acesso (SANDERS, 2011).

\subsection{Olhar, compreender, interagir e respeitar: ouvindo quem cuida}

A interpretação da criança, especialmente com limitações na comunicação verbal ou não verbal exige além da destreza, disponibilidade e sensibilidade. A discussão de Franco (2015) sobre trabalho criativo e cuidado em saúde ilumina o contexto do cenário estudado por valorizar o protagonismo dos trabalhadores no cotidiano, a partir das necessidades dos usuários e dos imprevistos.

Nas entrevistas com os profissionais de saúde buscou-se entender: o conhecimento destes sobre o conceito de subjetividade, se as questões subjetivas das crianças são observadas e atendidas no cuidado por eles prestado, como se dão os processos intersubjetivos com as crianças na assistência e nos aportes tecnológicos e como se comunicam com a criança com limitações ou impossibilidades para se expressarem.

Sobre o entendimento do conceito de subjetividade, as respostas foram múltiplas: características pessoais do indivíduo; opiniões individuais; diferentes formas de demonstrar emoções e agir; coisas que são sentidas e não necessariamente expressadas; sentimentos relacionados à várias coisas internas e construções em nível social; diferentes visões e pontos de vista; campo oposto da objetividade; observações pessoais; pensamentos; algo que não é palpável (Maicon, Alice, Paula, Sol, Laura, Vitória e Lana). Ao serem questionados se a subjetividade da criança era contemplada durante os seus atendimentos, Paula e Sol afirmaram que sim; Lana, em alguns momentos sim; Vitória, 
não necessariamente e Maicon não sabe se chega a esse ponto. Alice e Lana discursaram mais profundamente sobre sua atuação e suas razões:

\begin{abstract}
Procuro. Nem sempre eu consigo. (...) Quando a criança é um bebê, eu acho que você conseguir entender o que ela quer naquele momento é através do olhar que você consegue, através dos sinais que ela te dá. Às vezes ela está irritada, está com sono... você respeitar esse momento, você deixar se ela não está precisando de mim naquele momento, de intervenção (....) Se vou para um maiorzinho, é um cístico, eu [pergunto]: como você está agora, o que você está fazendo? Vamos começar o atendimento? Se a clínica dele permite... No momento, se ele estiver em insuficiência respiratória, aí é outro assunto. Mas se a clínica me permite, eu tento respeitar as características de cada um também (Alice/fisioterapeuta, 23/04/2020).
\end{abstract}

Essa percepção de Alice sobre as especificidades da faixa etária, individualidade da criança, adequação do atendimento com o padrão de sono e a irritabilidade, buscando o bem estar e o entendimento do quadro clínico, está relacionada à sensibilidade, a experiência profissional e a autonomia para agir. Alice atua na unidade, com esse perfil de crianças há 12 anos. Observando-se sua atuação constata-se que seu discurso é coerente com a prática, tanto no cuidado direto, como quando está na função de preceptora dos residentes. Tal perfil que coaduna sensibilidade técnica e capacidade docente é comentado por Dejours (2017) que considera os níveis clínicos, teóricos e práticos como alicerces para a sensibilidade à escuta, interpretação e espontaneidade. $\mathrm{O}$ posicionamento do profissional de saúde e a sensibilidade em suas atitudes e práticas são definidos por Dejours (2012) como inteligência inventiva, trabalho criativo, trabalho vivo, dinâmico, construído a partir da demanda das situações.

Lana relata suas dificuldades no atendimento a essas crianças:

\begin{abstract}
Aqui eu acho que é bem difícil, por conta das patologias delas. Porque a maioria, às vezes não fala. Ou então, quando vai falar é bem demorado (...). Tem um atraso bem considerável no desenvolvimento delas. Então, acho complexo de a gente conseguir entender algumas coisas de crianças que, no geral, são acamadas. Eu fico pensando, o que está se passando ali? Ah, coloca um DVD, coloca um filme, um desenho, alguma coisa. Mas será que é aquilo mesmo que ela quer, será que é aquilo mesmo que ela gosta, será que aquilo ali está de acordo com a idade dela, será que ela se entende como daquela idade? (Lana, enfermeira, 05/07/2020).
\end{abstract}

O desenvolvimento físico e cognitivo, nesse contexto, nem sempre pode ser compreendido com base em padrões predeterminados, pensados dentro de uma norma coletiva. Há singelas particularidades, comportamentos físicos e psíquicos que fazem sentido apenas se avaliados dentro do contexto de vida, de família, de processo de adoecimento daquela criança. O relato de Lana coincide com as similares observações feitas no cenário de pesquisa. Por exemplo, dentre as crianças internadas nos momentos de observação, sete estavam no processo de hospitalização muito prolongada e tinham 
condições complexas de saúde, padrões completamente diferentes de alimentação, mobilidade, contexto social e familiar e percepções de espaço e de mundo. Fora desse grupo, ainda havia crianças com doenças crônicas que passam boa parte do tempo em seus domicílios, mas que se internam com muita frequência. Muitos desses meninos e meninas possuem diversos agravos e sintomas relacionados ao corpo, à mente e precisam de aparatos tecnológicos para sobreviverem.

Atender as demandas desses pequenos seres em formação pode ser muito difícil para quem tem a percepção fragmentada e pautada apenas pela lógica do modelo biomédico. E é muito oportuna a reflexão de Canguilhem (2011) sobre normal, patológico, doença, cura, saúde, norma, vida e limites. O autor oferece subsídios para uma prática de cuidado orientada para a singularidade, a flexibilidade e o respeito ao fluxo da vida de cada organismo, o que exige capacidade de reformulação, adaptação, dinamismo, enfrentamento e superação de cada ser vivo, de cada pessoa. Nesse mesmo sentido, Laura (nutricionista, 02/06/2020) aponta que:

O perfil de criança com quem a gente trabalha, você não o tem descrito em livro, é muito difícil você ter algum lugar para buscar bases. Quando tem, são diretrizes muito rígidas, pois são situações muito singulares.

A maleabilidade da vida e a capacidade de adaptação e readaptação de cada organismo, contextualizadas por Canguilhem (2011), são percebidas por Laura, que busca atender às demandas físicas e subjetivas das pessoas que ela atende:

\footnotetext{
Então, você [tem que] conseguir discutir isso com os outros membros da equipe para traçar um plano único, porque acho também muito ruim cada profissional chegar com um discurso diferente. Você conseguir unificar esses discursos para ter um discurso único com a família, trazer para uma relação de confiança para que tenha adesão, conseguir trocar as informações, você conseguir escutar e é, utilizar as informações que vêm da criança e do acompanhante, acho que é um desafio diário. (Laura, nutricionista, 02/06/2020)
}

Os relatos já citados demonstram que o trabalho com crianças hospitalizadas em condições complexas de saúde precisa de: flexibilidade e sensibilidade dos profissionais, de respeito ao tempo da criança quanto à sua vontade e necessidades (de sono, por exemplo); de uma leitura cautelosa de cada contexto para se estabelecer o cuidado conforme demanda individual e não apenas execução do que está prescrito; de conhecer e levar em conta o desenvolvimento físico e cognitivo específico de cada uma. As entrevistadas também assinalam a necessidade de um plano terapêutico personalizado para cada criança, a partir de um trabalho multiprofissional e de escuta da criança e de seus responsáveis. Nesse último caso, conseguir uma relação de confiança que conduza à adesão às propostas terapêuticas por parte dos familiares é fundamental. 
As falas e as observações aqui discutidas estão em consonância com Backes e Azevedo (2017) que discutem a importância da associação dos elementos estruturais que dão subsídios à execução técnica com os elementos afetivos, espontâneos, cooperativos e compartilhados na gestão do cuidado.

\subsection{Aprender, compreender, interpretar e agir: a práxis do profissional de saúde}

O conhecimento científico e técnico é básico para o exercício do cuidado hospitalar. A atuação profissional é precedida por cursos técnicos, de graduação e de pósgraduação e seguida de uma formação continuada. No cenário aqui estudado, a demanda vai além do que a academia, os livros e manuais instrumentais podem ensinar. A discussão desta temática neste texto está fundamentada em observação etnográfica e em entrevistas. O trabalho empírico demonstra e confirma que a formação em saúde precisa ser permanente porque não há linearidade nos casos e cenários e que as exigências da realidade ultrapassam o saber estruturado.

Para se prestar um cuidado integral à criança é necessário um olhar sensível e perspicaz, construído na aliança da teoria com a experiência cotidiana. $\mathrm{O}$ fato de ela sofrer condições crônicas complexas de saúde exige dos profissionais de saúde um olhar peculiar, pois é possível que os prognósticos para as fases de crescimento e de desenvolvimento sejam diferentes do que a literatura aponta para crianças sem tais problemas na mesma idade. Por isso, é preciso disposição, sensibilidade e vivacidade para o desafio do cuidado diário de lidar com a diversidade clínica e subjetiva de crianças nas condições já mencionadas.

Em sendo um hospital de ensino o espaço médico aqui estudado, é importante lembrar que durante a internação, ao mesmo tempo em que a criança é atendida, ela é também instrumento de aprendizado para os que dela cuidam. Um hospital caracterizado como instituição de ensino tem algumas especificidades: nele atuam profissionais experientes (os mestres e tutores) e inexperientes (os aprendizes: residentes e internos). Essa estrutura traz benefícios e propicia que os profissionais vão se aprimorando no próprio ambiente em que se treinam e atuam. No entanto, tal dinâmica de permanente renovação exige uma pedagogia sistemática e reflexiva sobre os pacientes que são atendidos, tanto no que concerne aos aspectos técnicos como aos subjetivos e intersubjetivos. Pois, deixadas apenas ao mecanicismo do modelo biomédico, a criança e 
sua família passam a ser submetidas às ordens médicas e sem direito de expressão, em troca de tratamento e cuidado.

Furtado e Camilo (2016) apontam que o conhecimento, como instrumento de trabalho está associado ao poder e ao estímulo de comportamentos e padrões esperados. O modelo de estrutura hospitalar condiz com o conceito de biopoder apresentado por Foucault e descrito por esses autores, nas formas anatomopolíticas do corpo e biopolítica em relação à população. As falas dos profissionais entrevistados, ao elucidarem inquietações e desafios do cotidiano da assistência às crianças que são o foco deste estudo chamam atenção para os cuidados em circunstâncias tão delicadas. Suas reflexões demonstram que se preocupam com as relações, as negociações, os esclarecimentos mútuos de dúvidas entre eles, as crianças e as famílias, significando que a intersubjetividade é valorizada e pauta os cuidados. No entanto, os comportamentos são diversos entre os profissionais que se revezam nas rotinas e também ocorrem condutas típicas do modelo biomédico e tecnocrático de poder.

Alice, que atua na enfermaria de pediatria há 12 anos afirma que encontra muitos desafios na parte técnica e pessoal. Esses desafios são usados por ela como fonte de aprendizado:

E a cada desafio, a gente vai aprendendo, a gente vai interagindo melhor com a equipe, a gente vai crescendo na parte técnica, a gente vai crescendo na parte profissional. (...) Você aprende a cada dia. E é um hospital escola. Os residentes te estimulam a isso. Então eu vejo como um constante crescimento (Alice, fisioterapeuta, 23/04/2020).

A percepção de Alice quanto ao processo de aprendizado a partir dos encontros e desafios denota um exercício ético, sendo este um método para se chegar à dose certa de teoria e prática, racionalidade e sensibilidade do fazer competente para seres humanos por inteiro (RIOS, 2010). Abertura e flexibilidade tornam as relações mais fáceis e o trabalho mais agradável. É possível driblar o rigor técnico, sem deixar de lado a segurança do paciente e a ética, quando se coloca o sujeito como cerne do processo de trabalho, respeitando-o e oferendo-lhe a assistência a que tem direito, como preconizado pela Política Nacional de Humanização (BRASIL, 2003). Essa política, que parte de uma crítica ao modelo tecnocrático do exercício da medicina, estimula a comunicação entre gestores, trabalhadores e usuários, induzindo mudanças na gestão e na oferta de cuidados no SUS. Uma de suas importantes diretrizes é sobre o acolhimento que engloba a escuta qualificada, o compromisso e o vínculo. 
A implantação e a manutenção da Política de Humanização nas instituições hospitalares servem de amparo e estratégia no enfrentamento dos desafios. Pode-se dizer que não há como sistematizar o cuidado, porque ele é fruto de compreensão, empatia e solidariedade, por isso, por mais que os protocolos se direcionem para estratégias resolutivas, a realidade evoca criatividade e ultrapassa os limites do trabalho técnico. A fala de Vitória deixa claros os desafios individuais e de gestão, as imprevisibilidades, os desafios da desospitalização e o esforço para desfragmentar o cuidado.

Os meus principais desafios, aqui, está em contornar a imprevisibilidade, o que é uma coisa muito difícil. Outra questão que está muito no campo do desafio é a desospitalização. (...) O que fazer para tirar essas crianças de dentro do hospital? proporcionando que outras venham, e que essas crianças tenham o mínimo de convívio ou próximo de um convívio social, comunitário, familiar, maior do que o que elas têm hoje. Então, eu diria assim, além disso, eu considero um grande desafio desfragmentar esse cuidado (Vitória, médica, 05/07/2020).

Os apontamentos de Vitória ressaltam, como os anteriores, que o cuidado da criança em condição crônica complexa de saúde extrapola o campo das ciências médicas. $\mathrm{O}$ modelo de atenção precisa atender amplamente às necessidades da criança e da sua família, respeitando sua autonomia, seus valores e seus conhecimentos (RIBEIRO, 2019). Conforme recomendado pela Política Nacional de Humanização é preciso haver interação com troca de saberes e afetos entre profissionais, usuários e gestores (BRASIL, 2009).

A fala de Sol assinala, de forma muito sensível, a necessidade de aliança entre áreas do conhecimento, e relata seu aprimoramento e amadurecimento no decorrer da sua formação profissional:

Para mim, não é qualquer criança doente. (...) Isso para mim, no início foi muito difícil de entender. (...) Não é só criança doente, é toda uma família, um contexto social tão grande que vai além da doença delas. Então assim, eu me imagino no lugar, mas eu tento me olhar assim, e tentar pensar o quanto essa criança depende da gente, de ser um suporte e apoio, porque a questão social é muito forte aqui dentro. E eu não conseguia ver essa questão social quando eu entrei. Para mim, era só criança com gastrosquise. Não, mas aquela criança de gastrosquise tem que sair daqui com neocate, quem vai comprar esse neocate, quem vai suprir isso pra essa criança (Sol, residente de enfermagem, 21/05/2020).

A sensibilidade clínica que aparece no discurso dos profissionais se contrapõe às famosas críticas da prevalência do modelo biomédico e tecnocrata dentro das instituições hospitalares. Alguns fatores talvez possam impactar o estilo da assistência aqui constatado, como por exemplo: o fato do cenário de pesquisa ser uma instituição de atenção, ensino e pesquisa; o perfil das crianças atendidas exigir períodos de hospitalização prolongada o que as torna receptivas às abordagens e aos cuidados; as 
famílias desses meninos e meninas irem se adaptando ao processo de adoecimento crônico e à dependência de tecnologias. Mas, por mais que esse universo pareça "doméstico" aos vários atores, existem imprevistos técnicos e relacionais que evocam destreza, empatia e compreensão nas condutas e palavras. Na fala de Maicon que atua na assistência direta às crianças isso fica claro:

\begin{abstract}
A gente trabalha numa enfermaria que tem característica de unidade intensiva. Tanto que todos os pacientes são monitorizados, alguns dependem de respiradores e numa hora de adversidade a gente encontra essa dificuldade. Porque o paciente pode soltar uma fixação de traqueostomia e você tem que saber atuar naquele momento porque a vida daquele paciente depende de raciocínio rápido" (...) "Em relação à mãe, a gente tem que saber o que fala e até na hora de pensar também. Às vezes um pai está nervoso porque está vendo o filho daquele jeito e ele acaba colocando a emoção dele para fora. Então, eu acho que a gente não deve bater de frente com os pais porque a gente tem que tentar entender o lado deles também. É uma dificuldade que a gente tem que saber lidar dentro de uma enfermaria de hospital, porque eles vão expor o sentimento deles naquela hora e você não pode deixar se levar pelo sentimento deles. Você tem que saber lidar com a emoção dos outros (Maicon, técnico de enfermagem, 23/04/2020).
\end{abstract}

A mudança do perfil epidemiológico e demográfico impactou no processo de saúde e doença da população pediátrica brasileira contribuindo para o surgimento de uma nova pediatria. Foram necessárias mudanças no modelo de atenção à saúde para atender integralmente essas crianças tanto na prevenção de doenças quanto no gerenciamento das doenças crônicas, pois graças ao aprimoramento tecnológico e científico, as que antes não sobreviveriam, hoje sobrevivem (MOREIRA; GOLDANI, 2010).

O preparo tecnológico e o conhecimento científico surgem na fala de Maicon em conexão com o pensamento veloz, com presteza para ação e habilidade para lidar com as emoções dos familiares das crianças internadas, demonstrando sua elevada capacidade intersubjetiva. Observa-se comprometimento, responsabilidade, consciência da importância da autogestão emocional e do preparo para manejar os aparatos tecnológicos. Importante reafirmar aqui, que não foram apenas livros e técnicas que o tornaram um excelente profissional de saúde e sim a integração do campo técnico para manter o corpo vivo com o campo intersubjetivo que compreende, acolhe e cuida da dor da alma do outro e sua também.

O cuidado hospitalar, particularmente no caso das crianças aqui estudadas, também engloba a assistência ao processo de morte e o preparo do corpo, atividade essa de extrema dificuldade emocional tanto para os profissionais como para as famílias. Pitta (2008) comenta que a morte, se Idade Média estava nas salas de visita, hoje está nos hospitais, controlada pelos trabalhadores da saúde, que cuidam dos vivos e dos falecidos. 
Embora, é preciso dizer que muita coisa mudou depois que Pitta publicou sua obra, pois hoje, mais que anos atrás, muitas pessoas estejam preferindo viver seus últimos momentos no lar, junto a seus familiares. Essa etapa do cuidado é pouco discutida na formação acadêmica e no cotidiano profissional, mesmo sendo inerente ao trabalho na unidade de atuação. Paula, ao ser questionada sobre dificuldades em relação à sua atividade, comenta:

\begin{abstract}
Ainda em relação ao óbito. Você vê que até hoje eu não entrei no óbito (Obs.: ela se refere ao preparo do corpo pós-morte). Não é só quando a criança já veio a óbito. Até o processo, tipo assim, quando a criança está com fibrose aqui com a gente, que a gente sabe que já está no processo, isso aí também me dá um bloqueio (Obs.: ela se referia à criança com fibrose cística no processo de finitude da vida) (Paula, técnica de enfermagem, 18/05/2020).
\end{abstract}

O encontro com a finitude da vida e o cuidado com o corpo pós-morte merecem ser tratados com muito respeito e delicadeza. Além do significado para a criança que vivencia o falecimento, esse é um momento especial para o familiar que o assiste, assim como para os profissionais. A perda de uma criança marca quem está envolvido emocional ou profissionalmente com ela. É importante ressaltar que Paula atua como profissional de enfermagem na enfermaria de pediatria há 12 anos, sendo o preparo do corpo pós-morte uma das suas atribuições. O corpo sem vida, nesse contexto, é um objeto de trabalho. Ela (conforme relato) passa o cuidado para outro colega e se distancia. A dificuldade que sente reforça a afirmação de que o conhecimento e a competência não são advindos apenas da academia. Precisam ser construídos e reconstruídos na prática individual e coletiva, levando em conta também os limites do profissional de saúde. É preciso discutir, por exemplo, a razão desse bloqueio, porque essa dificuldade impacta na assistência à criança e à família. Ou seja, esse é um tema que precisa fazer parte da formação continuada e de um necessário apoio psicológico aos que lidam com a questão. Assistir o morrer é tão grandioso quanto assistir o nascer. Santos e Moreira (2014) destacam a necessidade de encarar o tema da finitude da vida e a morte na formação do profissional em saúde e na gestão do trabalho. Exemplo desse cuidado é citado em Neto e Kernkraut (2019) que após percepção do sofrimento e das dificuldades dos residentes de medicina em lidar com o sofrimento, com a impossibilidade de cura e com morte, criaram um grupo reflexivo para tratar dessas questões, o que resultou na minimização do sofrimento e na melhoria na formação profissional. Esse espaço de escuta e compartilhamento permitiu aos residentes expressarem suas manifestações subjetivas de medo, sofrimento e dor, e trabalhar as questões relativas à transferência na relação médico-paciente. 
Em resumo, a construção do conhecimento é contínua e inacabável. Esse processo, dentro do espaço estudado, possui uma beleza ímpar. A intersubjetividade, a alteridade e os desafios parecem evocar constantes transformações e crescimento das pessoas, fazendo de um espaço doloroso como uma enfermaria pediátrica, um jardim de aprendizado e valorização de todos os momentos. O reconhecimento de cada conquista da criança e de cada sucesso no processo de cuidado fortalece a todos os que nele se envolvem. Juntos acabam por reconhecer que a prática profissional vai além de sinais e sintomas. Abrange dimensões da vida que pulsa nas crianças, em seus familiares e em todos os que delas cuidam, num processo recursivo de intersubjetividade.

\section{Conclusões}

As habilidades profissionais para o cuidado integral de crianças em condições crônicas complexas de saúde são construídas cotidianamente, baseadas nas necessidades de cada uma, englobando os aspectos físicos, subjetivos, coletivos e história de vida. Essa construção conecta a objetividade da clínica com a subjetividade e a intersubjetividade, onde potências, limites e desafios são inerentes ao processo de trabalho e de aprendizagem dos profissionais de saúde.

O cenário de internação pediátrica estudado, por atender crianças com alto grau de especificidade clínica e pertencer a uma instituição de assistência e ensino, é um excelente espaço para o desenvolvimento e aprimoramento de todas as tecnologias envolvidas no cuidado, inclusive as leves (das relações). A subjetividade e intersubjetividade são a alma propulsora da dinâmica da vida na enfermaria: é gente cuidando de gente através do toque, do olhar, da fala, da escuta, dos procedimentos, da execução técnica e do domínio tecnológico, da disposição de estar junto.

A densidade do ambiente, os aparatos tecnológicos, as rotinas e protocolos, a "submissão" ao plano terapêutico e ao corpo profissional, podem não pesar tanto quando a pessoa é concebida com afeto, empatia e respeito. A ciência e as tecnologias de cuidado quando acrescidas de olhares sensíveis e acolhimento, podem regenerar o corpo e acalentar a mente e o coração.

O engajamento, a liberdade e a criatividade do profissional aparecem no estudo como pontos importantes para as estratégias de trabalho, demonstrando que a flexibilidade para adaptação de rotinas, quebras de protocolos (desde que dentro da ética e das normas segurança para o paciente e para a instituição) são inerentes ao cuidar. Os 
profissionais vão construindo, no decorrer dos atendimentos, pela comunicação intersubjetiva, planos terapêuticos maleáveis que contribuem para a minimização dos efeitos negativos da hospitalização. Eles se preocupam em estar capacitados para uma assistência integral e humanizada.

As limitações deste trabalho se devem às dificuldades de entendimento e de reflexão da pesquisadora de campo, uma vez que não houve limitações à presença e às atividades de pesquisa por parte do coletivo que atua na unidade de internação pediátrica. O processo foi construído com base teórica hermenêutica e atenção aos aspectos subjetivos também das pesquisadoras para que a vivência em campo enriquecesse ainda mais a compreensão da realidade.

\section{Referências}

ANDRADE, A.P.M.; MALUF, S.W. Cotidianos e trajetórias de sujeitos no contexto da reforma psiquiátrica brasileira. In: FLEISHER, S.; FERREIRA, J. (org.). Etnografias em serviços de saúde. Rio de Janeiro: Garamond, 2014. p. 33-54.

ARANTES, A.C.Q. A morte é um dia que vale a pena viver. Rio de Janeiro: Sextante, 2019.

BACKES, J.C.; AZEVEDO, C.S. Os paradoxos do trabalho em equipe em um Centro de Tratamento Intensivo Pediátrico (CTI-Pediátrico): explorando as articulações psicossociais no trabalho em saúde. Rev. Interface, Botucatu, v.21, n. 60, p. 77-87. 2017.

Disponível em:

https://www.scielo.br/j/icse/a/YphFycc5DwYD67GJbVYvvsf/?format=pdf\&lang=pt. Acesso em: 15 jun. 2020.

BRASIL. Política Nacional de Humanização. Brasília, 2003.

Disponível em: http://redehumanizasus.net/politica-nacional-de-humanizacao/. Acesso em: 08 set. 2020.

BRASIL. Humaniza SUS - Gestão Participativa e Cogestão. Série B. Textos básicos de saúde. Brasília, 2009.

Disponível em: http://bvsms.saude.gov.br/bvs/publicacoes/gestao_participativa_cogestao.pdf Acesso em: 11 set. 2020.

BRASIL. Conselho Nacional de Saúde. Resolução no 466, de 12 de dezembro de 2012. Brasília, 2012.

Disponível em: https://bvsms.saude.gov.br/bvs/saudelegis/cns/2013/res0466 1212 2012.html Acesso em: 01 out. 2020.

BRASIL. Conselho Nacional de Saúde. Resolução n 510, de 07 de abril de 2016. Brasília, 2016.

Disponível em: http://conselho.saude.gov.br/resolucoes/2016/Reso510.pdf\%20. Acesso em: 01 out. 2020.

CANGUILHEM, G. O normal e o patológico. 7. ed. Rio de Janeiro: Forense Universitária, 2011. 
CECÍLIO, L. C. O.; MERHY, E.E. A integralidade do cuidado como eixo da gestão hospitalar. Texto livre, Campinas, p. 1-19, mar. 2003.

Disponível em: http://www.hmdcc.com.br/wp-content/uploads/2018/04/Cecilio-A-

INTEGRALIDADE-DO-CUIDADO-COMO-EIXO-DA-GEST\%C3\%83O-HOSPITALAR.pdf Acesso em: 24 set. 2020.

DEJOURS, C. Sexualidade e trabalho. Trabalho vivo. Tomo II (trabalho e emancipação). Brasília: Paralelo15, 2012.

DEJOURS, C. Psicodinâmica do trabalho: casos clínicos. Porto Alegre - São Paulo: Dublinense, 2017.

DESLANDES, S.F. Humanização: revisitando o conceito a partir das contribuições da sociologia médica. In: DESLANDES, S. F. (org.). Humanização dos cuidados em saúde: conceitos, dilemas e práticas. Rio de Janeiro: Fiocruz, 2008. p. 33-47.

FERNANDES, C.A. Discurso e sujeito em Michel Foucault. São Paulo: Intermeios, 2012.

FEUERWERKER, L.C.M.; CECÍLIO, L.C.O. O Hospital e a formação em saúde: desafios atuais. Ciência \& Saúde Coletiva, Rio de Janeiro, v. 12, n.4, p. 965-97, 2007.

Disponível em: https://www.scielo.br/pdf/csc/v12n4/15.pdf Acesso em: 20 set. 2020

FOUCAULT, M. Vigiar e punir. Trad. Raquel Ramalhete. 20. ed. Petrópolis: Vozes, 1999.

FRANCO, T.B. Trabalho criativo e cuidado em saúde: um debate a partir dos conceitos de servidão e liberdade. Rev. Saúde Soc., São Paulo, v. 24, n. 1, p. 102-114, 2015.

Disponível em: https://www.scielo.br/pdf/sausoc/v24s1/0104-1290-sausoc-24-s1-00102.pdf Acessado em: 07 ago. 2020.

FURTADO, R.N.; CAMILO, J.A.O. O conceito de biopoder no pensamento de Michel Foucault. Revista Subjetividades, Fortaleza, v.16 n. 3, p. 34-44, dez. 2016.

Disponível em: http://pepsic.bvsalud.org/pdf/rs/v16n3/03.pdf. Acesso em: 10 jul. 2020

GADAMER, H. Verdade e Método: traços fundamentais de uma hermenêutica filosófica. 15. ed. Petrópolis: Editora Vozes, 1999.

GEERTZ, C. A interpretação das culturas. Rio de Janeiro: Zahar, 1978.

MALINOWISKI B. The argonauts of the Western of Pacific. London: Routledge, 2005.

MELLO, D.F. et al. Nursing care in early childhood: contributions from intersubjective recognition. Rev Bras Enferm, Brasília, v.70, n.2, p. 446-450, mar./abr. 2017.

Disponível em: https://www.scielo.br/pdf/reben/v70n2/0034-7167-reben-70-02-0446.pdf.

Acesso em: 25 ago. 2020.

MENEZES, L.A. et al. Conceitos, abordagem clínica e reflexões. In: Carvalho, M.S.N. et al. (org). Desospitalização de crianças com condições crônicas complexas. Rio de Janeiro: Eldorado, 2019. p. 35-75

MERHY, E.E. Saúde: a cartografia do trabalho vivo. 4. ed. São Paulo: Hucitec, 2014.

MINAYO, M. C. S. O desafio do conhecimento: Pesquisa qualitativa em saúde. 11. ed. São Paulo: Hucitec, 2008. 
MINAYO, M. C. S.; COSTA, A. P. Técnicas que fazem uso da palavra, do olhar e da empatia: pesquisa qualitativa em ação. São Paulo: Hucitec, 2019.

MOREIRA, M.E.L.; GOLDANI, M.Z. A criança é o pai do homem: novos desafios para a área de saúde da criança. Rev. Ciência \& Saúde Coletiva, Rio de Janeiro, v. 15, n. 2, p. 321-327, 2010. Disponível em:

https://www.scielo.br/j/csc/a/sxMsJk4kqp5j5vv3JKYXccf/?format=pdf\&lang=pt. Acesso em: 15 set. 2020.

PITTA, A. Hospital: dor e morte como ofício. 3. ed. São Paulo: Hucitec, 2008.

RIBEIRO, C.T.M. et al. Perspectivas de atuação multiprofissional. In: Carvalho, M.S.N. et al. (org.). Desospitalização de crianças com condições crônicas complexas: Perspectivas \& Desafios. Rio de Janeiro: Eldorado, 2019. p. 103-136.

RIOS, I.C. Subjetividade Contemporânea na Educação Médica: a formação humanística em medicina. 2010. Tese (Doutorado em Ciências) - Faculdade de Medicina da Universidade de São Paulo, São Paulo, 2010. Disponível em: https://teses.usp.br/teses/disponiveis/5/5137/tde27082010-143815/publico/IzabelCristinaRiosDoutorado.pdf. Acesso em 05 ago. 2020.

SANDERS, J. Cuidado centrado na família da criança durante a doença e a hospitalização. In: HOCKENBERRY, M.J.; WILSON, D. (org). Fundamentos de enfermagem pediátrica. 8. ed. Rio de Janeiro: Elsevier, 2011. p. 675-702.

SANTOS, R.A.; KOEPPE, G.B.; CARVALHO, M.S.N. Espaço para profissional de saúde versus intersubjetividade: relato de experiência. Revista Nursing, São Paulo, v.23, n.265, p. 4269-4272, maio. 2020.

SANTOS, R.A.; MOREIRA, M.C.N. Resiliência e morte: o profissional de enfermagem frente ao cuidado de crianças e adolescentes no processo de finitude da vida. Rev. Ciência \& Saúde Coletiva, Rio de Janeiro, v. 19, n.12, p. 4869-4878, 2014.

Disponível em: https://www.scielo.br/pdf/csc/v19n12/pt 1413-8123-csc-19-12-04869.pdf

Acesso em: 19 set. 2020.

Recebido em: 07 de outubro de 2020.

Aceito em: 22 de agosto de 2021. 